\title{
Pancytopenia: A multidisciplinary assessment of hemato-etiological and clinical spectrum in a tertiary care hospital
}

\author{
Katti T.V. ${ }^{1}$, Anand A.S. ${ }^{2}$,Patil T. ${ }^{3}$, Seshagiri K.S. ${ }^{4}$ \\ ${ }^{1}$ Dr. Trupti Vyasrao Katti, Profess or, ${ }^{2}$ Dr. Anantharao Shankar Anand, Professor \& HOD, ${ }^{3}$ Dr. Tejeshwini Patil, Assistant \\ Professor, ${ }^{4}$ Dr. Sangeeta Seshagiri K., Third year Post Graduate Student, all authors are affiliated with Department of \\ Pathology, Navodaya Medical College, Raichur, Karnataka, India.
}

Corres ponding Author: Dr. Anand A.S, Professor \& HOD, Department of Pathology, Navodaya Medical College, Raichur, Karnataka, India, Email: asanand27@gmail.com

\begin{abstract}
Background: The causes of pancytopenia range from simple, completely treatable diseases to serious life-threatening conditions. A thorough evaluation of these cases is mandatory as it would benefit the patients to receive appropriate treatment. Objectives: Evaluation of etio-hematological and clinical spectrum of pancytopenia. Settings and Design: A prospective study of two years (Jan 2016 -December 2017) was conducted on pancytopenic patients, attending Navodaya Medical College, Hospital and Research Centre, Raichur, Karnataka. Material and Methods: Etio- hematological and clin ical evaluation was done considering the relevant biochemical and serological investigations. Results: A total number of 1368 of cases were diagnosed as pancytopenia. The patients' age ranged from 19 to 68 years and M: F ratio was 2.1:1. Most frequent clinical symptom was generalized weakness $(90 \%)$ and least was bony pain (2\%). Peripheral smear examination revealed predominantly macrocytic blood picture $(47.9 \%)$. Bone marrow aspiration was performed in 444 cases (32.4\%), among which Megaloblastic anaemia (Exclusive and Combined with iron deficiency anemia) was the commonest (52.7\%). Etiologies of pancytopenia in decreasing order of frequency included Megaloblastic anemia $\{935$ cases $(68.4 \%)$ - Exclusive type (713 cases; 52.2\%) and Combined with iron deficiency anemia $(222$ cases; $16.2 \%) \mathrm{z}$, followed by Dengue fever (141 cases;10.3\%), Hypoplastic/Aplastic anemia [106 cases;7.8\% (Drug induced - 4 cases; $0.2 \%)$ ], Septicemia (60 cases;4.5\%), Leukemia (46 cases;3.25\%), Chronic malaria (46 cases ;3.25\%) and Myelodys plastic syndrome (34 cases; $2.5 \%$ ). Conclusion: Keeping in mind varied et iologies of pancytopenia, thorough diagnostic evaluation is required to achieve better clinical outcome.
\end{abstract}

Keywor ds: Clinical spectrum, Etio-he matological profile, Pancytopenia, Serological and Biochemical investigations.

\section{Introduction}

Pancytopenia is an important commonly encountered hematological condition characterized by a triad of findings that results from a number of disease processes - primarily or secondarily involving the bone marrow leading to decrease in all three lineages of blood cells [1]. The underlying mechanis ms other than decrease in hematopoietic cell production are marrow replacement by abnormal cells, suppression of marrow growth and differentiation, ineffective hematopoiesis, defective stem cell formation, antibody mediated sequestration, destruction and trapping of cells in an overactive reticuloendothelial system [2,3]. Etiologies of this condition can be due to common diseases like nutritional anemias, drug induced myelosuppression and infections such as malaria, kala azar or dengue, to

Manuscript received: $4^{\text {th }}$ June 2018

Reviewed: $14^{\text {th }}$ June 2018

Author Corrected: $20^{\text {th }}$ June 2018

Accepted for Publication: $23^{\text {rd }}$ June 2018 life threatening conditions like aplasia, myelodysplasias and leukemias [4]. The prevalence and risk factors vary in different geographical areas depending on life style, nutritional status and exposure to chemical or biological myelotoxins. A wide range of clinical and hematological manifestations are exhibited due to broad spectrum of etiologies of pancytopenia.

An early detection of underlying pathology helps in timely diagnosis and therapeutic intervention favoring a better clinical outcome $[5,6]$. Hence, this study was thus undertaken to evaluate cases of pancytopenia in Raichur, Karnataka state.

\section{Objectives}

1. Evaluation of hemato-etiological and

2. Clinical spectrum of cases of pancytopenia 


\section{Original Research Article}

\section{Materials and Methods}

Place and type of study- This prospective study of 2 years (January 2016-December 2017) comprised of 1368 cases of pancytopenia who attended Navodaya Medical College, Hospital \& Research Centre, Raichur, Karnataka. A detailed analysis of hematological, different etiologies and clinical findings were done.

Sampling methods and sample collection- A thorough clinical history was taken along with general and systemic examination of patients. Various hematological and serological parameters were analyzed and are as follows:

i) Hematology- Using semi automated hematology analyzer Pentra ES 60, CBC ( $\mathrm{Hb} \%$, red cell indices, total and differential leucocyte count, platelet count) along with grading of anemia, leucopenia and thrombocytopenia was done, while peripheral smear study by Leishman stained blood smears. Features observed in the latter were: RBC-Anisopoikilocytosis, nucleated RBCs and morphological type of anemia; WBC - Hypersegmented neutrophils, toxic granulation, relative lymphocytosis and immature cells/ blasts; Platelets- Normal, small \& giant forms and Screening for hemoparasites. Reticulocyte count was estimated on New Methylene Blue stained smears. Bone marrow aspiration was performed wherever feasible after obtaining written consent from the patients. The procedure was done using Salah's needle, the aspirate obtained was spread on the glass slides which were subsequently stained by Leishman's \& Giemsa stain and observed for cellularity, myeloid: erythroid (M:E) ratio, erythropoiesis, myelopoies is, megakaryopoiesis, lymphocytes, plasma cells, bacteria/parasites/ fungal elements, blast cells and other infiltrative disorders. Blasts were categorised as per WHO and FAB classification criteria. Special stains with Myeloperoxidase (MPO) and Periodic acid Schiff reagent (PAS) were done on peripheral smears \& bone marrow smears, wherever required.

ii) Relevant biochemical investigations included serum iron, ferritin, Vitamin B12 \& folate studies and c-reactive protein (CRP).

iii) Serological tests with Rapid Card Malaria test and Dengue card test (NS1, IgM and IgG) were performed in suspected cases.

\section{Inclusion criteria}

Patients between 18-70 years of age whose hemoglobin values recorded $<12 \mathrm{gm} / \mathrm{dl}$ (in males) and $<11 \mathrm{gm} / \mathrm{dl}$ (in females) respectively, total leucocyte count < $4000 / \mathrm{mm}^{3}$ and platelet count $<1.5 \mathrm{lakh} / \mathrm{mm}^{3}$ (As per WHO guidelines).

\section{Excl usion criteria}

1. Patients $<18$ years and $>70$ years of age.

2. Those cases who received whole blood or component therapy.

3. Patients on chemotherapy or radiotherapy.

\section{Results}

A total number of 1368 of cases were diagnosed as pancytopenia. Age of cases ranged from 19 to 68 years, maximum (74\%) were in 41-50 years age group, males (68\%) outnumbered females (32\%) and M: F ratio was 2.1:1.

Among clinical features, generalized weakness (1231 cases; 90\%) was most common, while bony pain (27 cases; $2 \%)$ was least common (Refer table 1).

Table-1: Overall distribution of clinical features in pancytopenic cases.

\begin{tabular}{|c|c|c|}
\hline Clinical Features & No. of cases & Percentage (\%) \\
\hline Generalized weakness & 1231 & 90 \\
\hline Pallor & 903 & 66 \\
\hline Dyspnoea & 684 & 22 \\
\hline Fever & 300 & 6 \\
\hline Bleeding Manifestations & 82 & 5 \\
\hline Jaundice & 68 & 21 \\
\hline Splenomegaly & 287 & 9 \\
\hline Hepatomegaly & 123 & 3 \\
\hline Ly mphadenopathy & 41 & 2 \\
\hline Bony Pain & 27 & \\
\hline
\end{tabular}

He matological findings: i) Hemog lobin values varied from 2.6 to $8.4 \mathrm{~g} \mathrm{~m} \%$, mean corpuscular volume (MCV) from 48.2 to $110.5 \mathrm{fl}$, mean corpuscular hemoglobin $(\mathrm{MCH})$ from 14 to $35.2 \mathrm{pg} / \mathrm{ml}$ and mean corpuscular hemoglobin concentration (MCHC) from 0.5 to $46 \mathrm{gm} / \mathrm{dl}$. Leucocyte count ranged from 500 to $3600 / \mathrm{mm}^{3}$, while platelet count from 12,000 to $1,20,000 / \mathrm{mm}^{3}$. Range of blood cell parameters observed is illustrated in table 2. 


\section{Original Research Article}

Table-2: Distribution of hematological parameters.

\begin{tabular}{|c|c|c|}
\hline Parameters & Range & Present study \\
\hline Hemoglobin $(\mathrm{g} \mathrm{m} \%)$ & $1.5-5$ & $246(18 \%)$ \\
\hline & $5-8$ & $958(70 \%)$ \\
\hline Total leucocyte count (cells/mm3 ) & $>8$ & $164(12 \%)$ \\
\hline & $500-1000$ & $109(8 \%)$ \\
\hline & $1001-2500$ & $533(39 \%)$ \\
\hline Platelet count (cells/mm3) & $2501-3900$ & $725(53 \%)$ \\
\hline & $10 \mathrm{k}-50 \mathrm{k}$ & $259(19 \%)$ \\
\hline & $50 \mathrm{k}-1 \mathrm{lakh}$ & $656(48 \%)$ \\
\hline & $1 \mathrm{lakh}-1.5$ lakh & $451(33 \%)$ \\
\hline
\end{tabular}

ii) On peripheral smear examination, varying degree of anisopoikilocytosis was observed, predominantly tear drop cells followed by target cells, schistocytes, mic rospherocytes and few cases (6.3\%) showed nucleated RBCs. Morphologically, macrocytic anemia (656 cases; 47.9\%) was commonest (Fig 1), followed by dimorphic (478 cases; 34.9\%), mic rocytic hypochromic (179 cases; 13.1\%) and normocytic normochromic (55 cases; 4.1\%) blood picture (Fig 2). Hypersegmented neutrophils were seen in 586 cases $(42.8 \%)$, to xic granulation in 80 cases $(5.8 \%)$ and relative ly mphocytos is was noted in 309 cases $(22.6 \%)$. Few patients (46 cases; 3.3\%) showed blasts of either myeloid or ly mphoid lineage. Rat io of platelet morphologies where, giant: small: normal was noted as 2.3:1:9.6. Hemoparasites were seen in 46 cases out of 1368 cases (2.7\%), where Plas modium falciparum (36 cases; 78.2\%) was more frequent (Fig 4) compared to Plasmodium vivax (10 cases; $21.8 \%)$.

iii) Reticulocyte count was normal in $48 \%$, increased in $32 \%$ and decreased in $20 \%$ of cases.

iv) Bone marrow aspiration was performed in 444 cases ; those with hypercellularity (316 cases; 71.2\%) was most common, followed by hypocellular (105 cases; $23.6 \%$ ) and normocellular marrow (23 cases; 5.2\%).

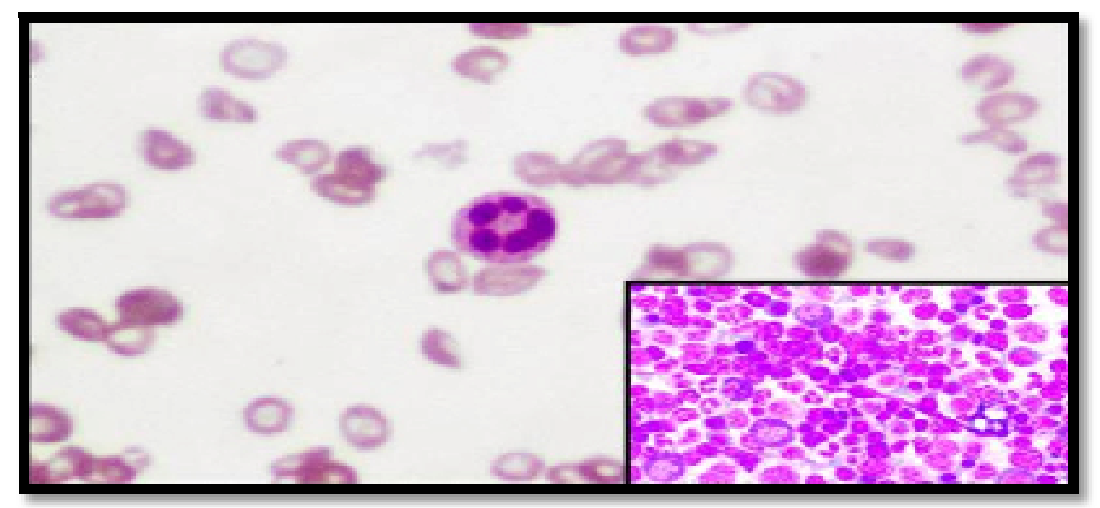

Fig-1: Peripheral smear showing macrocytic blood picture with segmented neutrophil (5 lobes) (Leishman's stain x400), with inset of bone marrow aspiration showing megaloblastic erythropoies is (Leishman's stain $\mathrm{x} 400$ ).

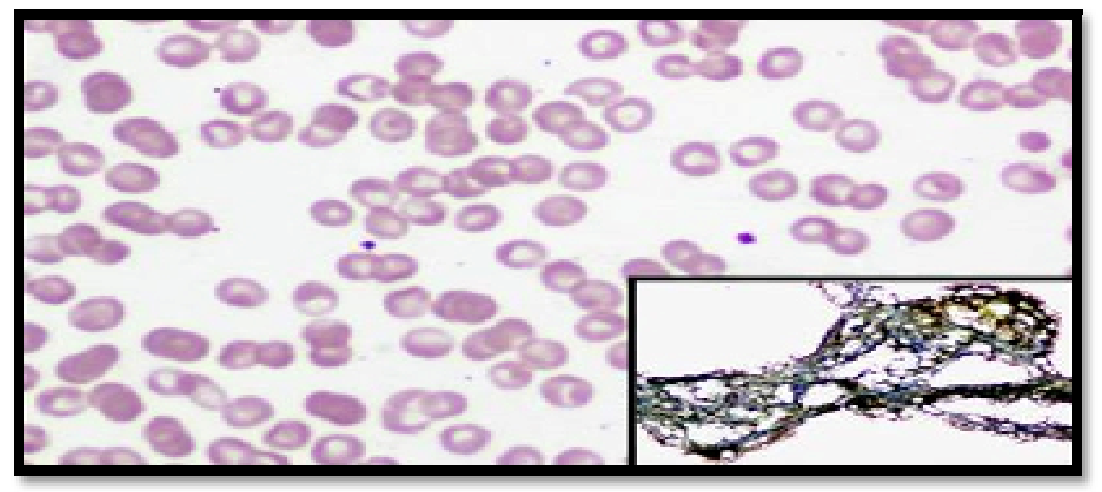

Fig-2: Peripheral smear showing normocytic normochro mic blood picture ( Leishman's stain $\mathrm{x} 400$ ) with inset of bone marrow aspiration showing aplastic marrow with increased fat (Leishman's stain x400). 


\section{Original Research Article}

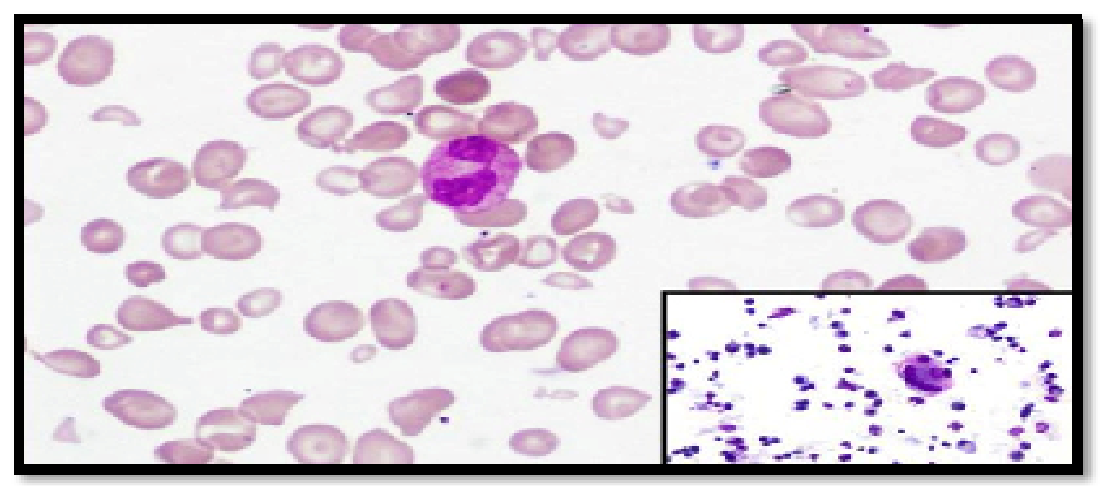

Fig-3: Peripheral smear showing Pelger Huet ano maly (Leish man's stain x 400), with inset of bone marrow as piration showing dysmyelopoiesis (Leishman's stain $\mathrm{x} 400$ ).

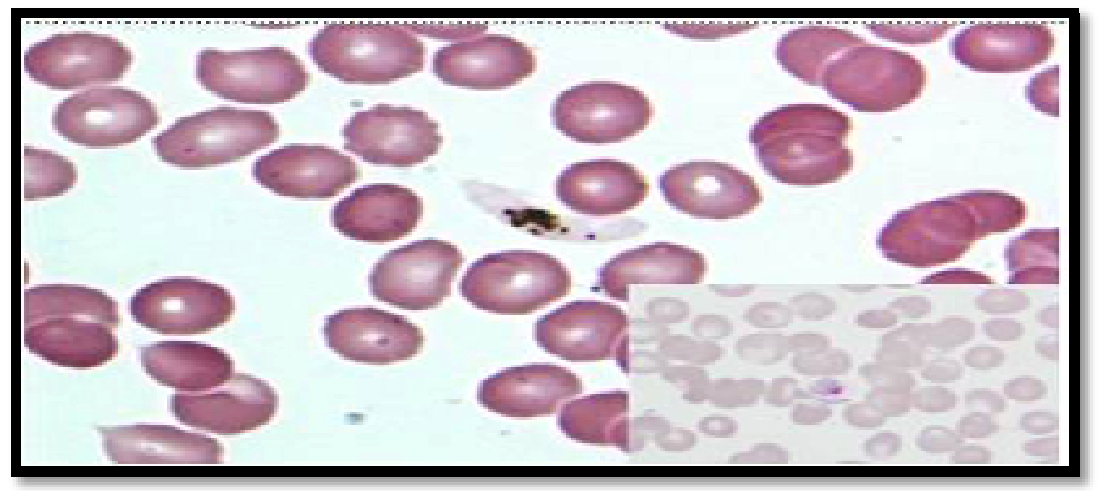

Fig-4: Peripheral smear showing gametocyte form of Plasmodiu m falciparum

(Leishman's stain x400) with inset showing schizont forms of Plasmodium vivax (Leishman's stain x400).

Among the morphological categories of marrow, exclusive megaloblastic erythropoiesis (152 cases; $34.2 \%$ ) was most frequent (Fig 1), followed by aplasia (105 cases; 23.6\%) (Fig 2), combined megaloblastic and micronormoblastic erythroid hyperplasia (82 cases; 18.5\%), leukemia (46 cases; 10.4\%), myelodysplasia (35 cases; $7.9 \%$ ) (Fig 3) and normoblastic erythropoiesis (24 cases; $5.4 \%$ ). No hemoparasites/granulomas /parasites /fungal elements were noted. The most common etiology was megaloblastic anemia [935 cases; $68.4 \%$ - exclusive ( 713 cases; $52.2 \%$ ) and comb ined with iron deficiency anemia (222 cases; 16.2\%)], while the least common cause was myelodysplastic syndrome (MDS- 34 cases; $2.5 \%$ ) (Refer table 3 ).

Table-3: Distribution of spectrum of etiologies of pancytopenic cases.

\begin{tabular}{|c|c|c|}
\hline Etiologies & No of cases & Percentage (\%) \\
\hline $\begin{array}{c}\text { Megaloblastic anaemia } \\
\text { (with and without mic ronormoblastic erythroid hyperplasia) }\end{array}$ & 935 & 68.4 \\
\hline Dengue fever & 141 & 10.3 \\
\hline Hypoplastic/Aplastic anaemia & 106 & 7.8 \\
\hline Leukemia & 46 & 3.2 \\
\hline Myelodysplastic syndrome & 34 & 2.5 \\
\hline Septicemia & 60 & 4.5 \\
\hline Malaria & 46 & 3.2 \\
\hline Others & - & - \\
\hline
\end{tabular}

Four cases were drug induced where two patients diagnosed as rheumatoid arthritis were on gold treatment, one with bronchial asthma and one with SLE were on steroid therapy. Out of total leukemic cases, 38 were AML M2 (82.6\%) and 8 were ALL L1 (17.4\%). All etiological categories presented with symptoms like generalised weakness, pallor, dyspnoea and fever, while petechiae was noted in cases with dengue and leukemia. Patients with malaria, dengue and drug induced 


\section{Original Research Article}

aplastic anemia presented with jaundice; whereas two cases of leukemia (AML M2) had bony tenderness. Clinically, splenomegaly was observed in 425 cases $(45.5 \%)$ of megaloblastic anemia, 30 cases of malaria $(65.2 \%)$, 24 cases of leukemia $(52.2 \%)$ and 20 cases of MDS (58.8\%); whereas hepatomegaly was more predominant in leukemia (26.1\%), followed by MDS (23.5\%) and megaloblastic anemia (22.2\%). Ly mphadenopathy was present in 56 cases $(5.9 \%)$ of mega loblastic anemia, all the 28 cases $(100 \%)$ of aplastic ane mia and 10 cases $(21.7 \%)$ of leu kemia respectively.

Hematological variations in different etiolog ical g roups:

i) CBC: Majority of cases showed moderate anemia (70\%), followed by severe $(18 \%)$ and mild degree $(12 \%)$. Cases with high MCV values were more common $(60 \%)$ in this study and belonged to nutritional anemia category, followed by low values $(22 \%)$ which were observed in malaria and septicemia; while normal range was noted in rest of the cases (18\%). $\mathrm{MCH}$ and MCHC were variably low among all cases. Majority of cases had mild leucopenia (53\%), followed by moderate $(39 \%)$ and severe $(8 \%)$. Patients with moderate thrombocytopenia $(48 \%)$ were more common followed by mild $(33 \%)$ and severe degree $(19 \%)$.

ii) Peripheral s mear: Anisopoikilocytosis was most commonly seen in cases of megaloblastic anemia $(76 \%)$ compared to aplastic anemia (10\%), leukemia (4\%) and MDS (2\%). Microcytes, schistocytes and target cells were observed mainly in cases of septicemia (5\%) and rarely in patients with malaria and MDS ( $2 \%$ each). Presence of nucleated RBCs was mostly observed in MDS $(20 \%)$, followed by malaria (11\%), megaloblastic anemia combined with iron deficiency anemia $(8 \%)$ and leukemia [AMLM2 $(1 \%)]$.

The toxic granulation in neutrophils and shift to left in myeloid series were noted in septicemia cases (65\%), and hypersegmented neutrophils were observed in cases with megaloblastic anemia (62\%). Presence of blasts was predominant in leukemia (46 cases; $57.5 \%$ ) compared to MDS (34 cases; $42.5 \%$ ). Immature ly mphoid cells were most commonly found in cases of aplastic anemia (95\%), followed by megaloblastic anemia (22\%) and MDS (12\%). Peripheral smear study showed classical features of blasts of respective leukemia and were confirmed using special stains. Giant forms of platelets were mostly seen in patients with nutritional anemia (25\%), compared to septicemia ( $8 \%)$ and dengue cases $(6 \%)$, while smaller forms were observed in aplastic anemia and rest other cases showed normal platelets.

iii) Reticulocyte count: Increased count was observed in malaria, nutritional anemia and septicemic cases, whereas those with aplastic anemia and MDS showed reduced reticulocyte count.

iv) Bone marrow study: Varying degrees of dysmyelopoiesis was observed and was most predominant in MDS (98\%) followed by megaloblastic anemia $(86 \%)$.

\section{Discussion}

The demographic pattern of pancytopenia varies all over the world possibly due to the differences in methodology, stringent diagnostic criteria, duration of study, geographic distribution, genetic differences, age distribution, nutritional status, infections and exposure to myelotoxic agents [7].

In present study, maximum cases of pancytopenia (74\%) were observed in 41-50 years age group, which corroborated with the study of Shane et al (30 -55 years; 70\%), while Anita Javalgi et al documented higher proportion in 15-25 years (39.6\%) [6,8]. M:F ratio of this study (2.1:1) was in accordance with Lakey et al (2.6:1), while there was decline in the ratio in the studies conducted by Gayatri et al $(1.2: 1)$ and Anita Javalgi et al $(1.35: 1)$ [4,6,9]. Majority of the cases presented with weakness/ fatigue $(90 \%)$ followed by pallor $(66 \%)$ and dyspnoea $(50 \%)$, while a small proportion of patients had bleeding manifestations (6\%). Symptoms attributable to anemia or thrombocytopenia were more common in this study than those due to leucopenia. Similar observation was documented by Anita Javalgi et al [6]. Presentation of organomegaly \{splenomegaly (21\%), hepatomegaly (9\%) and ly mphadenopathy $(3 \%)\}$ and bony tenderness $(2 \%)$ was comparable to those of Gayatri et al, Khunger et al, Khodke et al and Anita et al [4,5,6,10].

\section{Hematol ogy}

i) CBC- The variations in hemoglobin value, leucocyte count and platelet count in this study were comparable to other authors' studies (Refer table 4). 


\section{Original Research Article}

Table-4: Comparis on of blood cell parameters.

\begin{tabular}{|c|c|c|c|c|}
\hline Parame ters & Range & $\begin{array}{c}\text { Anita J avalgi et al } \\
{[\mathbf{6}] \mathbf{( 2 0 1 3 )}}\end{array}$ & $\begin{array}{c}\text { GPK Reddy et al } \\
{[\mathbf{1 1}] \mathbf{( 2 0 1 6 )}}\end{array}$ & Present study \\
\hline \multirow{3}{*}{ Hemoglobin (g m \%) } & $1.5-5$ & $32(30.18 \%)$ & $17(40.5 \%)$ & $246(18 \%)$ \\
\cline { 2 - 5 } & $5-8$ & $58(54.71 \%)$ & $14(38.1 \%)$ & $958(70 \%)$ \\
\cline { 2 - 5 } & $>8$ & $16(15.09 \%)$ & $9(21.4 \%)$ & $164(12 \%)$ \\
\hline \multirow{3}{*}{$\begin{array}{c}\text { Total leucocyte count } \\
\text { (cells/mm3) }\end{array}$} & $500-1000$ & $5(4.71 \%)$ & $3(7.1 \%)$ & $109(8 \%)$ \\
\cline { 2 - 5 } & $1001-2500$ & $23(21.69 \%)$ & $22(52.4 \%)$ & $533(39 \%)$ \\
\cline { 2 - 5 } & $2501-3900$ & $78(7.58 \%)$ & $17(40.5 \%)$ & $725(53 \%)$ \\
\hline \multirow{3}{*}{\begin{tabular}{c} 
Platelet count (cells/mm3) \\
\cline { 2 - 5 }
\end{tabular}} & $10 \mathrm{k}-50 \mathrm{k}$ & $27(25.47 \%)$ & $22(52.4 \%)$ & $259(19 \%)$ \\
\cline { 2 - 5 } & $50 \mathrm{k}-1 \mathrm{lac}$ & $35(33.08 \%)$ & $9(21.4 \%)$ & $656(48 \%)$ \\
\cline { 2 - 5 } & $11 \mathrm{lac}-1.5 \mathrm{lac}$ & $44(41.50 \%)$ & $11(26.2 \%)$ & $451(33 \%)$ \\
\hline
\end{tabular}

The variations in the red cell indices (MCV, MCH and MCHC) were in accordance with the study of Nazish Shinwari et al [12].

ii) Peripheal s mear findings: Anisopoikilocytosis was observed commonly in cases of megaloblastic anemia (76\%), followed by hypoplastic/aplastic anemia (10\%), leu kemia (5\%) and MDS (1\%). Similar findings were noted by Gayatri et al and Khunger et al [4, 10] (Refer table 5). A mong the peripheral smear findings, macrocytic (48\%) was the commonest which was in accordance with Sweta et al (49\%), whereas Gayatri et al reported dimorphic anemia (37.5\%) as predominant type $[4,13]$. The least common blood picture was normocytic normochromic $(4 \%)$ in this study, while Sweta et al documented dimorphic blood picture as the lowest proportion (9\%) [13]. Nucleated RBCs were predominantly seen in cases of MDS followed by malaria in present study, while Khunger et al and Gayatri et al noted them mostly in MDS and leukemic cases $[4,10]$. Hypersegmented neutrophils were observed in $46.6 \%$ of total cases, whereas Tilak et al documented them in $84.9 \%$ of cases, on the contrary Khunger et al didn't document in any case of pancytopenia [10,14].

Immature WBCs were more commonly seen in cases diagnosed with leukemia, followed by MDS and megaloblastic anemia which was comparable to the studies of Khunger et al and Gayatri et al [4,10]. Majority of cases of hypoplastic / aplastic anemia (95\%) had relative ly mphocytosis whereas Tilak et al and Khunger et al reported lower percentage $(50 \%$ and $85.71 \%)[10,14]$. There are limited number of studies in literature regarding platelet morphology in cases of pancytopenia. Hemoparasite induced pancytopenia was documented in 46 cases $(3.25 \%)$, where all were diagnosed as malaria - i) On peripheral s mear examination in 38 cases, among which gametocytes of P. falciparum were detected in 28 cases while gametocyte, trophozoite and schizont forms of P. Vivax in 10 cases and ii) By Rapid card test in 8 cases which included P. falciparum in 5 cases and P. vivax in 3 cases. Similar study by Gayatri et al documented malaria in $1.9 \%$ of cases and noted gametocytes of P. falciparum on peripheral smear examination, while Anita Javalgi et al observed the same in $3.7 \%$ of cases on both peripheral smear and BMA smears; whereas Tilak et al reported malaria in $3.8 \%$ and kala azar in $2.5 \%$ of cases in their study $[4,6,14]$. The peripheral smear findings with respect to etiologies were comparable with other studies $[4,10]$ (Refer table 5).

Table-5: Comparison of peripheral smear findings of varied etiologies.

Study groups: (1) Khunger et al [10] (2002), (2) Gayatri et al [4] (2011), (3) Present study (2016-2017).

\begin{tabular}{|c|c|c|c|c|c|c|c|c|c|c|c|c|c|c|c|}
\hline \multirow[t]{2}{*}{ Etiologies } & \multicolumn{3}{|c|}{ Anisopoikilocytosis } & \multicolumn{3}{|c|}{ Nucleated RB C } & \multicolumn{3}{|c|}{$\begin{array}{l}\text { Hypersegmented } \\
\text { Neutrophils }\end{array}$} & \multicolumn{3}{|c|}{ Immature WBC } & \multicolumn{3}{|c|}{$\begin{array}{c}\text { Relative } \\
\text { Lymphoc ytosis }\end{array}$} \\
\hline & 1 & 2 & 3 & 1 & 2 & 3 & 1 & 2 & 3 & 1 & 2 & 3 & 1 & 2 & 3 \\
\hline Megal. A & $\begin{array}{c}97.2 \\
\%\end{array}$ & $\begin{array}{c}88.3 \\
\%\end{array}$ & $\begin{array}{l}76 \\
\%\end{array}$ & $\begin{array}{c}12.5 \\
\%\end{array}$ & - & $8 \%$ & - & $\begin{array}{c}49.3 \\
\%\end{array}$ & $\begin{array}{l}62 \\
\%\end{array}$ & $\begin{array}{c}12.5 \\
\%\end{array}$ & $\begin{array}{c}25.7 \\
\%\end{array}$ & $6 \%$ & $\begin{array}{c}97.2 \\
\%\end{array}$ & $\begin{array}{c}7.8 \\
\%\end{array}$ & $\begin{array}{l}22 \\
\%\end{array}$ \\
\hline Aplastic A & $\begin{array}{c}0.07 \\
\%\end{array}$ & $\begin{array}{c}89.4 \\
\%\end{array}$ & $\begin{array}{l}10 \\
\%\end{array}$ & - & - & - & - & $\begin{array}{c}26.3 \\
\%\end{array}$ & $1 \%$ & - & - & - & $\begin{array}{c}85.7 \\
\%\end{array}$ & $\begin{array}{c}52.6 \\
\%\end{array}$ & $\begin{array}{l}95 \\
\%\end{array}$ \\
\hline MDS & - & - & $1 \%$ & $50 \%$ & - & $\begin{array}{l}20 \\
\%\end{array}$ & $\begin{array}{l}25 \\
\%\end{array}$ & - & - & $75 \%$ & - & $\begin{array}{l}15 \\
\%\end{array}$ & - & - & $\begin{array}{l}12 \\
\%\end{array}$ \\
\hline Leukemia & $0.1 \%$ & $25 \%$ & $5 \%$ & $40 \%$ & $\begin{array}{l}25 \\
\%\end{array}$ & $1 \%$ & $\begin{array}{l}40 \\
\%\end{array}$ & - & $\begin{array}{l}12 \\
\%\end{array}$ & $\begin{array}{c}100 \\
\%\end{array}$ & $50 \%$ & $\begin{array}{l}75 \\
\%\end{array}$ & - & - & - \\
\hline Mal aria & - & $\begin{array}{c}100 \\
\%\end{array}$ & - & - & - & $\begin{array}{l}11 \\
\%\end{array}$ & - & - & - & - & - & - & - & - & - \\
\hline
\end{tabular}




\section{Original Research Article}

iii) Cases with normal Reticulocyte count (650 cases; $47.5 \%$ ) was more common in this study, compared to those with higher $(436$ cases; $31.9 \%$ ) and lower values $(282$ cases; $20.6 \%$ ), which corroborated with study by Gayatri et al who also documented predominantly normal values ( 82 cases; $77.4 \%$ ) fo llowed by lower values ( 24 cases; $22.6 \%$ ) [4].

iv) Bone marrow: Pancytopenia may be either due to cellular or hypocellular marrow, thus mandating the exploration of various etiologies. Out of the cases in which bone marrow aspiration was performed, cases with hypercellularity was more common (71.2\%) followed by hypocellularity (23.6\%) and normocellu larity (5.2\%). This was comparable to Anita et al, who documented hypercellular in $68.8 \%$, hypocellular in $16.2 \%$ and normocellular marrow in $15 \%$ of cases [6].

The morphological features of bone marrow were comparable with other studies. (Refer Table 6).

Table-6: Comparison of marrow mor phological categories.

\begin{tabular}{|l|c|c|c|}
\hline Marrow picture & $\begin{array}{c}\text { Lakey et al [9] } \\
\mathbf{( 2 0 1 0 )}\end{array}$ & $\begin{array}{c}\text { Ver ma N et al } \\
{[\mathbf{1 5} \text { (2012) }}\end{array}$ & $\begin{array}{c}\text { Present } \\
\text { study }\end{array}$ \\
\hline 1. Normocellu lar/ Normoblastic erythroid hyperplasia & $18.5 \%$ & $18.1 \%$ & $5.4 \%$ \\
\hline $\begin{array}{l}\text { 2. Micronormoblastic and Megaloblastic erythroid } \\
\text { hyperplasia }\end{array}$ & - & - & $18.5 \%$ \\
\hline 3. Megaloblastic erythroid hyperplasia & $24.2 \%$ & $40.2 \%$ & $34.2 \%$ \\
\hline 4. Leukemia & $20.3 \%$ & - & $10.4 \%$ \\
\hline 5. Myelodysplasia & $7.4 \%$ & $9.7 \%$ & $7.9 \%$ \\
\hline 6. Hypoplastic/aplastic anemia & $29.6 \%$ & $26.3 \%$ & $23.6 \%$ \\
\hline 7. Plas macytosis & - & $2.7 \%$ & - \\
\hline 8. Myelo fibrosis & - & $2.7 \%$ & - \\
\hline
\end{tabular}

Results of biochemical and serological tests were in accordance with similar study by GPK Reddy et al [11].

\section{Etiologies}

Table-7: Comparative study showing distribution of etiologies

\begin{tabular}{|l|c|c|c|c|c|}
\hline Etiologies & $\begin{array}{c}\text { Khunger et } \\
\text { al [10] (2002) }\end{array}$ & $\begin{array}{c}\text { Gayatri et } \\
\text { al [4] (2011) }\end{array}$ & $\begin{array}{c}\text { Shin wari et al } \\
[\mathbf{1 2}] \mathbf{( 2 0 1 2})\end{array}$ & $\begin{array}{c}\text { Reddy GP et al } \\
{[\mathbf{1 1} \text { ( 2016 ) }}\end{array}$ & $\begin{array}{c}\text { Present } \\
\text { study }\end{array}$ \\
\hline $\begin{array}{l}\text { Megaloblastic anaemia } \\
\text { (with and without mic ronor- } \\
\text { moblastic erythroid hyperplasia) }\end{array}$ & 72 & 74 & 27 & 38.1 & 68.4 \\
\hline Dengue fever & - & - & - & - & 10.3 \\
\hline Aplastic anaemia & 14 & 18 & 21 & 26.2 & 7.8 \\
\hline Leukemia & 5 & 3.5 & 23 & 9.5 & 3.2 \\
\hline Myelodysplastic syndrome & 2 & 3.5 & 1 & - & 2.5 \\
\hline Septicemia & - & - & 2 & 2.4 & 4.5 \\
\hline Malaria & 1 & 1.7 & - & 7.1 & 3.2 \\
\hline Others & 6 & - & 26 & 16.7 & - \\
\hline
\end{tabular}

The incidence of megaloblastic anemia in pancytopenic patients varies in literature from $0.8 \%$ to $32.26 \%$ [10]. Megaloblastic anaemia was observed to be the commonest cause of pancytopenia $(68.4 \%)$, which is in accordance with similar studies by Khunger et al (72\%), Tilak et al (64\%) and Gayatri et al $(74 \%)$ [4,10,14]. Among these cases, exclusive category was more common $(52.2 \%)$ when compared to those combined with iron deficiency anemia (16.2\%). In a similar study by Nazish Shinwari et al, megaloblastic anemia was documented in $27 \%$ of total cases where exclusive $(20 \%)$ was predominant followed by combined category (7\%) [12]. Hence there should be a periodical assessment to diagnose the nutritional anemias considering the diverse ethnic populations, different dietary habits and social customs in India $[\mathbf{6}, \mathbf{1 0}]$. The second common etiological group was dengue $(10.3 \%)$. This was in contrast to other studies which documented aplastic anemia (Refer table 5). The higher incidence of dengue in this region was likely due to lower socioeconomic status, poor sanitation, lack of awareness about the spectrum of clinical manifestations and increasing frequency of vague \& non-specific sy mptoms. 


\section{Original Research Article}

The incidence of aplastic/ hypoplastic anemia according to the literature varies from $\mathbf{1 0 \%}$ to $\mathbf{5 2 . 7 \%}$ [4,11]. The present study reported the same as the third common cause (7.7\%), whereas Gayatri et al (18.26\%) and Khunger et al (14\%) reported as second common etiology [4, 10]. Aplastic/ hypoplastic anemia may be due to triggering of aberrant immune response by viral infections, exposure to chemicals and drugs or endogenous antigens generated by genetically altered bone marrow cells, leading to active destruction of blood forming cells by lymphocytes [7,10]. Drug induced aplastic anemia is commonly seen in cases receiving therapy for rheumatoid arthritis, hyperthyroid conditions, tuberculosis, convulsive disorders and various inflammatory disorders. The outcome depends on:

i) Dose and duration of exposure and

ii) Susceptibility or idiosyncracy to the myelotoxin.

These usually cause mild reversible marrow suppression, but may occasionally progress to more severe damage [16]. Present study reported four cases of drug induced aplastic anemia accounting to $0.2 \%$ of total cases, among which two were on gold and two on steroid therapies; while Tilak et al also documented four such cases in $5.1 \%$ of pancytopenic patients among which, three were on chloramphenicol and one on streptomycin. Verma Nidhi et al reported three cases accounting to $4.2 \%$ and all were on chloramphenicol $[14,15]$.

Next common cause included leukemia which comprised of 46 cases, where 38 were AML M2 and 8 were ALL L1; whereas Gayatri et al reported 4 cases where three were AML M2 and one was ALL L2 [4].

The least common etio logies were septicemia (4.5\%), malaria (3.25\%) and MDS (2.5\%); while Reddy P et aldocumented septicemia in $2.4 \%$ and malaria in $7.1 \%$ of cases, respectively [11]. The incidence of malaria in other studies were : Khunger JM et al - 1\%; Tilak V et al $-3.9 \%$ and Kumar R et al - 3\% respectively $[3,10,14]$. MDS in this study was detected in thirty four cases $(2.5 \%)$ which was similar to Khunger et al (2\%), whereas Anita et al documented the same in $0.9 \%$ of total cases $[6,10]$.

The clinical features of pancytopenic cases considerably varied according to the spectrum of different etiologies. However, cases presenting with organomegaly and lymphadenopathy were comparable with the studies of Khunger et al and Gayatri et al $[4,10]$.

Clinical findings as per etiologies were compared. In cases of megaloblastic anemia, splenomegaly was more predominant in this study $(45.4 \%)$ compared to Khunger et al $(28.5 \%)$ and Gayatri et al $(27.7 \%)$, while hepatomegaly $(22.2 \%)$ was in accordance with the said authors' studies $(29.1 \%$ and $29.8 \%)$ and ly mphadenopathy was more common in present study (5.9\%) compared to Khunger et al (0.6\%) and Gayatri et al $(3.8 \%)[4,9]$.

The present study had no organomegaly in cases of aplastic anemia, whereas Gayatri et al documented both splenomegaly (21\%) and hepatomegaly (15.7\%), while Khunger et al documented only hepatomegaly (3.5\%). Ly mphadenopathy in this study was more common (26.4\%) compared to Gayatri et al (5.2\%).

In cases diagnosed as leukemia, Khunger et al documented higher incidence of splenomegaly (80\%) and hepatomegaly $(100 \%)$ compared to the present study $(52.1 \% ; 25 \%)$ and Gayatri et al $(25 \% ; 25 \%)$. Lymphadenopathy was observed more commonly in the study by Khunger et al (60\%) compared to present study $(21.7 \%)$.

The cases of MDS showed splenomegaly and hepatomegaly more frequently in the study of Khunger et al (75\%; $50 \%)$ when compared to present study $(58.8 \% ; 23.5 \%)$. Ly mphadenopathy was not seen in this study as well as the authors' studies.

Cases of malaria had splenomegaly more commonly in the studies of Khunger et al (100\%) and Gayatri et al (100\%) compared to this study $(65.2 \%)$, whereas hepatomegaly and ly mphadenopathy was not seen in either of the said studies $[4,9]$.

Among the frequent etiologies of pancytopenia in the world scenario, aplastic anemia is documented to be the commonest especially in countries like Israel, Europe, Bangladesh and India. Myelodysplastic syndrome and neoplastic diseases are the next common ones in Israel \& Europe, chronic malaria and kala azar in Bangladesh; while on the contrary, it was megaloblastic anemia in India [5]. 


\section{Original Research Article}

\section{Conclusion}

Keeping in mind the probable etiologies and large proportion of pancytopenia being reversible, a thorough evaluation is warranted to identify the underly ing pathology at the earliest, thus guiding the clinicians to implement pre ventive strategies and help the patients in achieving better clinical outcome.

\section{Contribution Details}

\begin{tabular}{|c|l|l|l|c|c|c|c|c|}
\hline $\begin{array}{c}\text { Names of } \\
\text { Authors }\end{array}$ & $\begin{array}{c}\text { Study } \\
\text { Concept }\end{array}$ & $\begin{array}{c}\text { Des } \\
\text { ign }\end{array}$ & $\begin{array}{c}\text { Acquisit } \\
\text { ion of } \\
\text { data }\end{array}$ & $\begin{array}{c}\text { Analysis \& } \\
\text { Inter pretiation } \\
\text { of data }\end{array}$ & $\begin{array}{c}\text { Compiled } \\
\text { literature } \\
\text { sources }\end{array}$ & $\begin{array}{c}\text { Drafting the } \\
\text { manuscript }\end{array}$ & $\begin{array}{c}\text { Checked } \\
\text { References }\end{array}$ & $\begin{array}{c}\text { Critical } \\
\text { Re vision }\end{array}$ \\
\hline $\begin{array}{c}\text { Dr. Trupti V } \\
\text { Katti }\end{array}$ & $\checkmark$ & $\checkmark$ & $\checkmark$ & $\checkmark$ & $\checkmark$ & $\checkmark$ & $\checkmark$ & $\checkmark$ \\
\hline $\begin{array}{c}\text { Dr. A.S. } \\
\text { Anand }\end{array}$ & $\checkmark$ & $\checkmark$ & $\checkmark$ & $\checkmark$ & $\checkmark$ & $\checkmark$ & $\checkmark$ & $\checkmark$ \\
\hline $\begin{array}{c}\text { Dr. } \\
\text { Tejeshwini } \\
\text { Patil }\end{array}$ & - & $\checkmark$ & $\checkmark$ & - & - & - & $\checkmark$ & $\checkmark$ \\
\hline $\begin{array}{c}\text { Dr. Sangeeta } \\
\text { Seshagiri }\end{array}$ & - & - & - & - & $\checkmark$ & & $\checkmark$ & - \\
\hline
\end{tabular}

What this study add to existing knowledge- Based on assimilation of data from previous studies and current research, there exists an overlap of certain clinico-hematological findings. As etiological spectrum of pancytopenia is varied and confounds the pathologists and clinicians, routine along with bone marrow and etiological based laboratory evaluation is warranted. The frequency of this hematological condition Pancytopenia, is on the rise and hence needs global attention.

Funding: Nil, Conflict of interest: None initiated Permission from IRB: Yes

\section{References}

1. Kar M, Ghosh A. Pancytopenia Journal. Indian Academy of Clin ical Med icine 2002; 3: 29-341.

2. Firkin F, Chesterman C, Penington D, Rush B. De Gruchy's Clinical Hematology in Clin ical Practice. $5^{\text {th }}$ Edition. London Blackwell Scientific Publications 1989; 119-36.

3. Kumar et al. Pancytopenia - A 6 year study. J Assoc Physicians India 2001; 49: 1079-81.

4. Gayatri B N, Satyanarayan K. Pancytopenia -A clinico-haematological study. Journal of Laboratory physicians 2011; 3(1): 15-20.

5. Khodke K, Marwah S, Buxi G, Yadav RB, Chaturvedi. Bone marrow examination in cases of pancytopenia. J Academy Clin Med 2001; 2: 55-59.

6. Javalgi AP, Dombale VD. Clinico - Hematological Analysis of Pancytopenia: A Bone Marrow Study. National Journal of Laboratory Medicine Dec 2013; 2 (4): 12-17.
7. Vaddatti T et al. Clinico-haematological profile of Pancytopenia- A South Indian tertiary hospital experience. Indian Journal of Pathology and Oncology July - September 2015; 2(3): 165-69.

8. Graham S, Marla NS, Fernandes H, Jayaprakash CS. A clinico-hematological evaluation of pancytopenia in a tertiary care hospital in South India. Muller Journal of Medical Sciences and Research Jan-Jun 2015; 6(1): 5-9.

9. Lakhey A, Talwar OP, Singh VK, KC Shiva Raj. Clin ico-Hematological Study Of Pancytopenia. Journal of Pathology of Nepal 2012; 2(3): 207-10.

10. Khunger JM, Arculselvi S, Sharma U, Ranga S, Talib H. Pancytopenia- a clinico-haematological study of 200 cases. Indian J Pathol Microbiol 2002; 45 (3): 375-79.

11. Reddy GPK, Kande V, Rao M. Clinical features and risk factors of pancytopenia: a study in a tertiary care hospital. International Journal of Advances in Medicine Feb 2016; 3(1): 68-72.

12. Shin wari S, Raziq F, Khan K, Uppal FT, Khan H. Pancytopenia: experience in a teriary care hospital of Peshawar, Pakistan. Rawal Medical Journal Oct-Dec 2012; 37(4): 370-73. 


\section{Original Research Article}

13. Barik SS, Chandoke RK, Verma AK. A prospective clinico-hematological study in 100 cases of pancytopenia in capital city of India. Journal of Applied He matology April-June 2014; 5(2): 45-50.

14. Tilak V, Jain R. Pancytopenia- A clinicohematological analysis of 77 cases. Indian J Pathol Mcrobiol 1992; 42(4): 339-404.
15. Verma Nidhi, Malik Harsh, Sharma Veena K, Agarwal Anil. Etiology of Pancytopenia in and around Meerut. Journal of Advance Researches In Biological Sciences 2012; 4(2): 145-51.

16. Mintzer DM, Billet SN \& Chamielewski L. Drug induced Hematologic Syndromes. Advances in Hematology 2009; 1-11.

\section{How to cite this article?}

Katti T.V, Anand A.S, Patil T, Seshagiri K.S. Pancytopenia: A multidisciplinary assessment of hemato-etiological and clin ical spectrum in a tertiary care hospital. Trop J Path Micro 2018; 4(4):365-374.doi:10. 17511/ jopm. 2018.14 .12 